\title{
Serious games para educação em higiene bucal infantil: uma revisão integrativa e a busca de aplicativos
}

\author{
Serious games for children's oral hygiene education: \\ an integrative review and application search
}

Emanuel Rodrigues Morais (https://orcid.org/0000-0002-3605-9579) ${ }^{1}$

Clarice Maria Araújo Chagas Vergara (https://orcid.org/0000-0003-1709-9951) ${ }^{1}$

Filipe Oliveira de Brito (https://orcid.org/0000-0002-2522-0056) ${ }^{1}$

Helena Alves de Carvalho Sampaio (https://orcid.org/0000-0001-5353-8259) ${ }^{1}$
${ }^{1}$ Universidade Estadual do Ceará. Av. Dr. Silas Munguba 1700, Itaperi. 60714903 Fortaleza CE Brasil. laila1alessia2@hotmail.com

\begin{abstract}
This article aims to perform an integrative review on publications that discuss the use of serious games focused on education of children's oral hygiene and a search for available apps with this same purpose. An integrative peer review was conducted in the databases IBECS, LILACS, SCIENCE DIRECT, SciELO, PUBMED, SCOPUS, MEDLINE and Scholar Google, from January to November of 2017 and in parallel a search of available applications on the Android ${ }^{\circledR}$ platform, and websites of computer science, such as the IEEE Xplore. In the integrative review, 12 articles were selected that fulfilled the inclusion criteria. In searches on websites, 11 games were classified as serious games aimed for oral hygiene. A total of 284 apps were identified at Play Store ${ }^{\circledR}$, with predominance for interventionist activity in dental offices, with pain, dental cavity and trauma being the main plots. Few applications focused on oral hygiene education are available. As for intended audience, there is the prevalence of children's public. Despite the scarcity of publications on the subject, exploring technological resources as educational options for children's oral hygiene indicate an area of knowledge with academic potential and possible applications for public health.
\end{abstract} Key words Video game, Health education, Oral hygiene
Resumo $O$ objetivo deste artigo é realizar uma revisão integrativa sobre as publicações que abordam o uso de serious games voltados para educação em higiene bucal infantil e uma busca dos aplicativos disponiveis com esse mesmo fim. Foi conduzida uma revisão integrativa pareada nas bases de dados IBECS, LILACS, SCIENCE DIRECT, SciELO, PUBMED, SCOPUS, MEDLINE e Google Acadêmico, de janeiro a novembro de 2017 e em paralelo uma busca de aplicativos disponiveis na plataforma Android ${ }^{\circledR}$ em sitios eletrônicos das Ciências da Computação, como o IEEE Xplore. Na revisão integrativa, foram selecionados 12 artigos que atenderam aos critérios de inclusão. Nas buscas em sítios eletrônicos, 11 jogos foram classificados como serious games voltados para higiene bucal. Foram identificados 284 aplicativos na Play Store ${ }^{\circledR}$, com predominio para atividades intervencionistas em consultório, sendo dor, cárie dental e trauma os enredos principais. Poucos aplicativos voltados para educação em higiene bucal estão disponíveis. Quanto ao público-alvo, há predomínio do público infantil. Apesar da escassez de publicações sobre o assunto, explorar recursos tecnológicos como meios de educação em higiene bucal infantil sinaliza uma área do conhecimento com potencial acadêmico e com possíveis aplicações para a saúde pública.

Palavras-chave Jogos de vídeo, Educação em saúde, Higiene bucal 


\section{Introdução}

As mídias digitais interativas alcançam a maioria dos espaços na sociedade contemporânea, ao mesmo tempo em que pesquisas provam a eficácia dos computadores no aumento da motivação e na consolidação do conhecimento durante o processo de ensino-aprendizagem ${ }^{1,2}$. Nesse contexto, os jogos computacionais se destacam quando comparados às outras mídias, pois possibilitam um equilíbrio entre o desafio e o envolvimento do jogador durante a interação ${ }^{3}$.

Os benefícios da utilização de tecnologias móveis (smartphones, tablets, notebooks, E-readers) para acesso a conteúdos educacionais têm recebido destaque por parte de alguns autores ${ }^{4-7}$, os quais utilizam o conceito de aprendizagem móvel (mobile learning ou m-learning). Para esses autores, aprendizagem móvel é definida como aprendizagem ampliada e apoiada a partir do uso de dispositivos móveis, com características como portabilidade, integração com diferentes mídias e não limitações física e geográfica dos usuários. Sob essa ótica, merecem destaque os serious games, jogos que têm como característica principal ensinar ou informar conceitos específicos de disciplinas ou treinar habilidades operacionais e comportamentais do jogador ${ }^{8}$.

Algumas dificuldades na Saúde impulsionaram a utilização dos serious games (jogos sérios). Entre elas, destacam-se a complexidade dos procedimentos, os custos de treinamento e de obtenção de materiais, bem como a necessidade de novas abordagens para reabilitação e ensino de hábitos saudáveis ${ }^{9}$. Serious games têm diversas finalidades, tais como: distração de pacientes em intervenções terapêuticas dolorosas, treinamento de profissionais, promoção da saúde, condicionamento físico e monitoramento da saúde ${ }^{10}$.

A utilização de serious games em treinamentos e simulações médicas apresenta, segundo pesquisas realizadas, as seguintes vantagens: baixo custo das plataformas de treinamento, ampla disponibilidade e portabilidade dos jogos, redução drástica no número de erros humanos e melhoria na execução de procedimentos específicos ${ }^{11}$. Dentro dos serious games aplicados à Saúde, destacam-se os direcionados à Odontologia, pois a demanda crescente de ferramentas para estimular a tomada de decisão, o treinamento, o ensino e a educação na área incentivam o desenvolvimento desse grupo de jogos ${ }^{9,12-15}$.

Diante o exposto, esta revisão integrativa da literatura foi realizada com o intuito de identificar publicações científicas que abordam o uso de serious games voltados para educação em higiene bucal infantil e buscar aplicativos disponíveis na Play Store e em sites especializados em desenvolvimento de jogos. Tais objetivos convergem para potenciais áreas cuja interdisciplinaridade entre a tecnologia e a promoção da saúde encontrem espaço para desenvolvimento.

\section{Método}

Foi realizada uma revisão integrativa por pares $^{16}$ nas seguintes bases de dados: IBECS, LILACS, SCIENCE DIRECT, SciELO, PUBMED, SCOPUS, MEDLINE e Google Acadêmico. Dois pesquisadores independentes fizeram as buscas para identificação dos estudos primários. Uma vez cumprida essa etapa, foi dado prosseguimento minucioso à análise dos estudos selecionados para estabelecer o corpus desta revisão. Como representante da literatura cinza, optou-se por incluir pequenos jornais e revistas, pesquisas não publicadas, conversas com especialistas, dados obtidos em dissertações e teses publicadas no banco de teses da Coordenação de Aperfeiçoamento de Pessoal de Nível Superior (CAPES), assim como artigos identificados em busca manual nas referências de artigos, especialmente nos de revisão extensiva e em outras revisões integrativas.

As buscas foram realizadas de janeiro a novembro de 2017, com delimitação inicial de tempo dos últimos sete anos. Foi feita uma busca em sítios eletrônicos especializados em conteúdos das Ciências da Computação, como o IEEE Xplore, por softwares voltados para higiene bucal infantil; uma busca de materiais educativos na forma de jogos computacionais desenvolvidos pelas empresas Colgate e Oral B; e pela Associação Americana de Odontologia (American Dental Association - ADA). Com vistas a ampliar o lastro da pesquisa, uma busca na Play Store foi conduzida com o propósito de verificar o que se dispõe de aplicativos desenvolvidos para plataforma Android $^{\varpi}$ com o mesmo fim.

A pergunta norteadora da pesquisa foi elaborada usando-se a estratégia P.V.O. ( $\mathrm{P}$ - População, V - Variável e O - desfecho): "Quais serious games são voltados para educação em higiene bucal de crianças?". Uma vez estabelecidas quais bases de dados seriam utilizadas, foram definidos os unitermos (descritores ou palavras-chave), usados para a captação das publicações. Essa escolha é de vital importância para acessar os documentos realmente relevantes para o objeto de estudo. 
Recomendam-se, de modo geral, unitermos que incluam a condição ou doença e a intervenção ou exposição avaliada como suficientes para a obtenção de trabalhos relevantes ${ }^{17}$.

A expressão geral de busca utilizada foi $((((()$ video games $[\mathrm{MeSHTerms}])$ AND oral hygiene [MeSHTerms]) AND health education [MeSHTerms]) AND children [MeSHTerms])))) ))). Em outra busca, optou-se por substituir o descritor vídeo games pelas palavras-chave serious game e jogo sério. Essa substituição foi propositada porque não houve achados com os descritores. O objetivo foi de ampliar o campo de busca.

Entre os critérios que determinaram a inclusão de um estudo, foi considerada a relevância com relação à questão de investigação, analisada a partir do título, dos descritores, do abstract e da conclusão. Os critérios de inclusão foram definidos com os seguintes parâmetros: a) delineamentos: estudos metodológicos, cujo objetivo tenha sido o desenvolvimento de tecnologia (jogo sério); b) População-alvo: crianças; c) Adesão: profissionais ou usuários que fizeram uso da tecnologia com fim educativo; d) Idiomas: português e inglês.

Os critérios de exclusão foram: a) artigos de revisão de literatura e editorial; envolvendo desenvolvimento de jogo sério ou aplicativo para outra finalidade que não higiene bucal; b) protocolos de estudos observacionais ou de intervenção.

Nesse processo, os estudos passaram por dois filtros para seleção e avaliação. O primeiro filtro foi a seleção de publicações relevantes. $O$ rastreamento inicial dos artigos foi realizado por dois pesquisadores e baseou-se na revisão do título e do resumo, que determinou o preenchimento dos critérios de elegibilidade. Essa etapa visou, inicialmente, o descarte de artigos que não atenderam aos critérios de inclusão. Cada pesquisador chegou a uma lista de estudos primários. As duas listas foram comparadas e chegou-se a uma única lista. Foram incluídos nesse primeiro filtro os estudos em que houve discordância na inclusão ou na exclusão. O fluxo de análise dos artigos neste primeiro filtro está descrito na Figura 1. Os doze estudos selecionados foram lidos na íntegra e suas referências foram examinadas manualmente.

O segundo filtro foi a seleção de dados relevantes. Neste, para cada trabalho aprovado pelo processo de seleção, os pesquisadores utilizaram um formulário para o qual extraíram todas as informações necessárias. Foram coletadas as se- guintes informações: autores, ano, objetivo, público-alvo, metodologia, resultados e conclusão, como exposto no Quadro 1.

Para descrição e análise, esses dados foram divididos, nesta pesquisa, em dois grupos: um que trata exclusivamente dos serious games e outro tratando de aplicativos voltados para a área de Odontologia. Os seguintes critérios foram usados: a temática explorada, crianças como público-alvo, distribuição da ferramenta (web e Play Store) e, especificamente no caso dos serious games, terem uma abordagem pedagógica.

Uma estratégia de busca foi efetuada em sítios eletrônicos de empresas que desenvolvem jogos e serious games. No Quadro 2, estão listados os repositórios pesquisados:

Os serious games selecionados foram: "Dental Space Odyssey", "Tooth brush patch, Dr. Rabbit Dentist", "ToothPaste Tower", "Dental Defenders", "Pasta contra bactérias", "Serious game", "To Tell the Tooth", "Quickbrush toothbrush", "Happy Teeth Kids", "Grush the Gaming toothbrush", "Uma aventura na floresta da Dentolândia".

\section{Resultados}

\section{Características dos estudos sobre serious games}

Nesta revisão, observou-se que cinco estudos, sendo eles quatro artigos e uma dissertação, foram realizados por uma equipe de pesquisadores e alinhavam-se como uma cadeia sequencial. São eles: "Serious games na Odontologia: aplicações, características e possibilidades"13; "Um serious game para educação sobre saúde bucal em bebês" ${ }^{12}$; "Planejamento de um serious game voltado para saúde bucal em bebês"14; "Definindo a abordagem de comunicação no planejamento de um serious game voltado para saúde bucal em bebês"15; e "Planejamento e desenvolvimento de um serious game voltado para saúde bucal em bebês" ${ }^{\prime 1}$. Esses estudos foram elaborados em cadeia tendo como objetivo o desenvolvimento de um serious game. Um artigo versou sobre uma revisão sistemática, na qual percebeu-se a carência de jogos com abordagem voltada para saúde bucal de bebês. Outro trouxe ao público o tipo de abordagem que foi utilizada para o desenvolvimento do jogo. Outro tratou das etapas de planejamento. E, por último, a dissertação apresentou o jogo 'Uma aventura da floresta da Dentolândia'18.

Na dissertação, a autora ressalta a carência de serious games voltados para bebês e para mães. $\mathrm{O}$ 


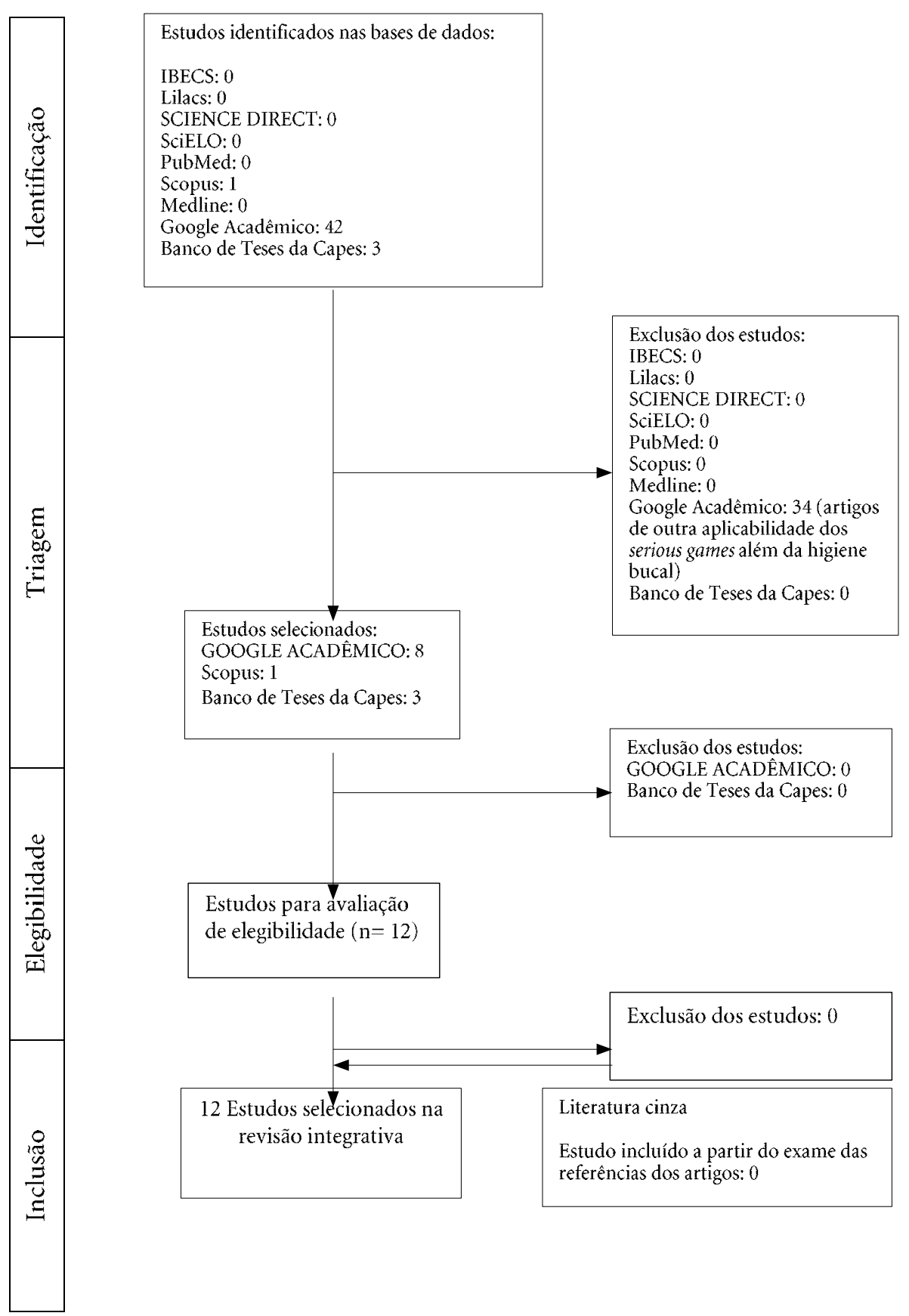

Figura 1. Fluxo de análise dos artigos. Fortaleza/CE, 2017.

Fonte: Elaborada pelo autor (2018).

produto apresentado foi o jogo "Uma aventura na floresta da Dentolândia", cuja metodologia de desenvolvimento foi baseada na Abordagem de Comunicão (AC) junto ao público-alvo. Segundo a autora, os dados foram analisados e apresentaram como resultados: “[...] 87\% das mães que jogaram aprenderam algum conhecimento novo e 53\% conseguiram ganhar (concluir com êxito) o jogo"18.

O PEPE é um jogo sério de apoio ao tratamento odontológico de crianças especiais como forma de abordagem lúdica por meio de um jogo 
Quadro 1. Sítios web pesquisados.

\begin{tabular}{|l|l|}
\hline \multicolumn{1}{|c|}{ Repositório } & \multicolumn{1}{c|}{ Endereço eletrônico } \\
\hline All doctors game & $\begin{array}{l}\text { http://alldoctorsgames.com/ } \\
\text { dentist }\end{array}$ \\
\hline Game salad & http://arcade.gamesalad.com \\
\hline Jogos de dentista & http://jogosdedentista.com \\
\hline Colgate & http://www.colgate.com.br \\
\hline Oral b & http://www.oralb.com.br. \\
\hline
\end{tabular}

Fonte: Elaborada pelo autor (2018).

sério para plataforma móvel. Foi pensado como estratégia de apoio durante intervenção odontológica e higiene oral da criança com Paralisia Cerebral. O jogo foi desenvolvido com base no design participativo centrado no usuário ${ }^{19}$, design de jogos e práticas das áreas de Interação Humano-Computador (IHC). O jogo é baseado em um cenário cartunizado e traz como personagem o Supersaliva, como alguns requisitos sobre a questão asséptica e sensor de movimentos integrado ao dispositivo. $\mathrm{O}$ aplicativo proposto foi avaliado durante o tratamento odontológico de 20 crianças, visando averiguar a sua eficiência enquanto facilitador do processo de escovação supervisionada, tendo apresentado resultados positivos ${ }^{20}$.

A dissertação 'Aplicando sistemas hápticos em serious games: um jogo para educação em higiene bucal $^{21}$ destaca-se pela incorporação de sistemas hápticos por ampliar o senso de realismo e trazer uma forma mais atraente de envolvimento. Traz como proposta um jogo imersivo. Também propõe um modelo de processo de desenvolvimento de serious games visando abordar um conjunto harmônico entre abordagem, conteúdo e tecnologia para um correto planejamento do jogo.

No artigo 'Uma proposta de serious game aplicado à educação em saúde bucal ${ }^{22}$, pretendese comprovar a utilidade do dispositivo háptico quanto à sua utilização em diferentes faixas etárias e sociais para educação em saúde bucal. O artigo apresentou uma proposta de concepção e desenvolvimento de um serious game baseado em realidade virtual para higiene bucal ${ }^{22}$.

A dissertação 'Criação, desenvolvimento e aplicação de serious game educativo para prevenção em saúde bucal infantil - Caí, perdi um dente... E daí?' reforça a escassez de materiais educativos para prevenção, principalmente aqueles voltados para o público infantil ${ }^{23}$. A proposta é apresentar o serious game Caí, Perdi um dente... E daí?, cuja temática explorada refere-se à avulsão dentária de dentes permanentes ${ }^{23}$. Baseou-se, também, à semelhança do PEPE, no design interativo centrado no usuário ${ }^{19}$.

Duas publicações trazem à comunidade científica uma perspectiva mais metodológica quanto ao uso dos serious games. 'Metodológica', no sentido aqui empreendido, assume o conceito e o direcionamento de um estudo de intervenção, tipo ensaio clínico randomizado. Tal sentido merece a devida atenção, uma vez que os outros trabalhos apresentados tinham como método de pesquisa ou uma revisão de literatura ou a concepção e o desenvolvimento de um serious game seguido de sua avaliação.

Esses estudos ganharam destaque devido ao debate que se levantou a respeito da sua inclusão. O debate entre os revisores é recomendável por ser reflexivo, crítico e produtivo, desde que o método seja preservado e seguido criteriosamente. No primeiro ${ }^{24}$, temos o protocolo de um ensaio clínico randomizado. Trata da fase II da intervenção e foi aplicado com crianças com alto risco de cáries e seus familiares. Segundo os critérios de exclusão, não seriam aceitos protocolos de pesquisas observacionais ou de intervenção, por exemplo. No segundo ${ }^{25}$, temos o artigo que foi produzido a partir dessa intervenção. A leitura na íntegra deste artigo foi o critério chave para inclusão de ambos. O protocolo foi incluído porque ele fundamentou o método de condução da pesquisa, que resultou no artigo 'Can oral health education be delivered to high-caries-risk children and their parents using a computer game? - A randomised controlled trial ${ }^{25}$

Assim foi o caso de outro estudo. A discussão foi levantada a partir dos termos "jogo digital", que conceitualmente difere do termo "serious games", e "saúde bucal", que é bem mais abrangente que "higiene bucal". De semelhante modo, após a leitura na íntegra do artigo 'Elaboração de um jogo digital educacional sobre saúde bucal direcionado para população infantil', optou-se pela sua inclusão, por ser relevante e coerente com o objetivo proposto.

O artigo 'Elaboração de um jogo digital educacional sobre saúde bucal direcionado para população infantil' trata do jogo "Dr. Trata Dente" ${ }^{\text {"26 }}$ e se baseou na abordagem de três diferentes tópicos sobre saúde bucal: a placa bacteriana, os métodos de higiene bucal para controle da placa bacteriana e da cárie dental e suas medidas preventivas. Esses tópicos foram expostos nas três fases do jogo. O Dr. Trata Dente é representado pela figura de um dentista, que desperta no imaginário infantil a imagem do super-herói que conversa com as crianças sobre saúde bucal du- 


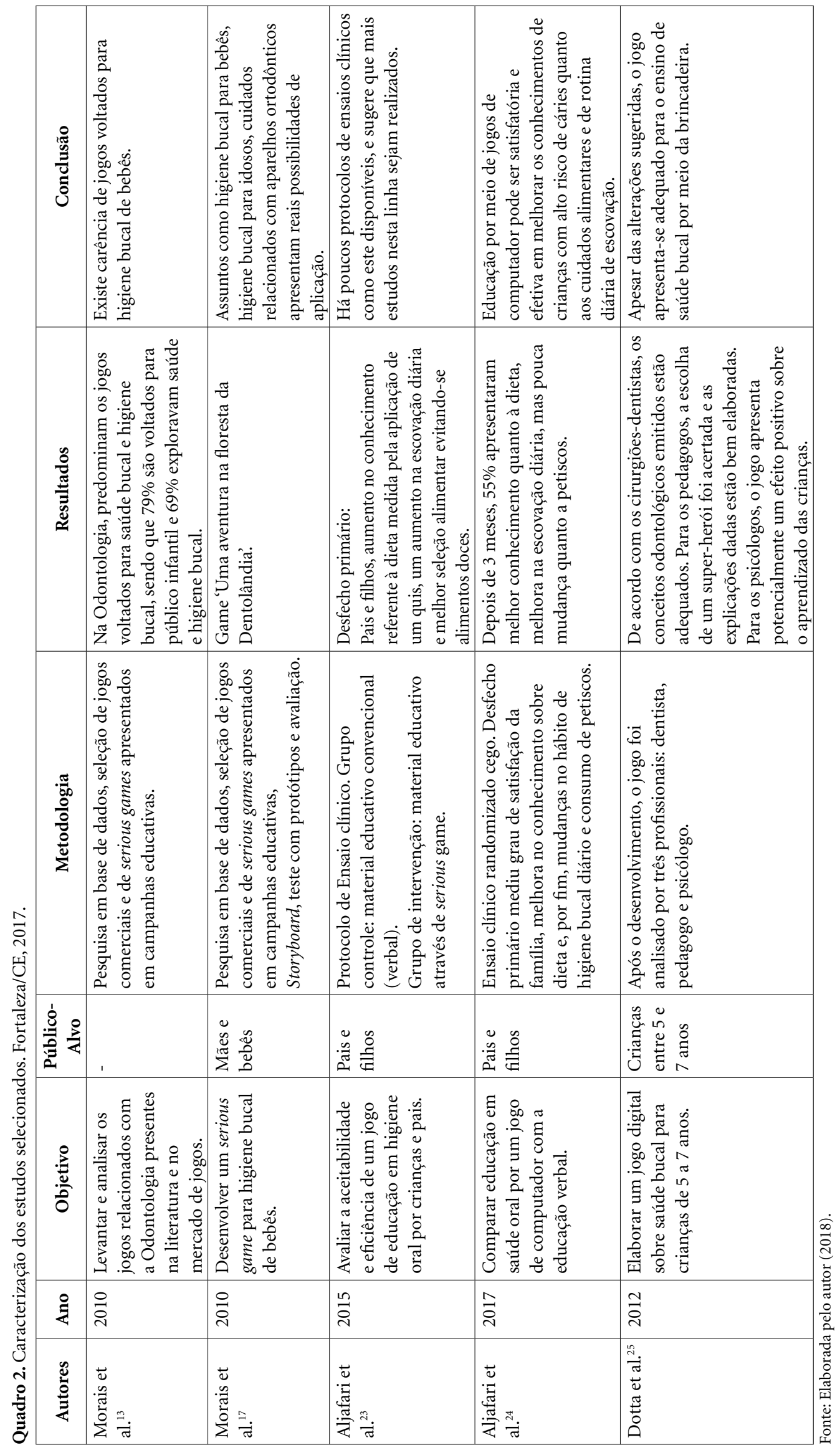


rante o jogo. Após seu desenvolvimento, o jogo foi analisado por profissionais da Odontologia, da Pedagogia e da Psicologia $(n=9)$.

\section{Busca de aplicativos em sítios eletrônicos específicos e na Play Store}

A busca nos sítios eletrônicos, com a finalidade de desenvolver jogos, e nas empresas especificadas do ramo da Odontologia, identificou-se 11 jogos classificados como serious games voltados para higiene bucal.

Na Play Store, foram encontrados 284 aplicativos voltados para Odontologia. Os softwares com enredo de consultório odontológico são predominantes quando comparados aos voltados para educação em higiene bucal. Em se tratando desse enredo (consultório), há uma abordagem presente em todos os jogos: ou o jogo trazia a estória de um personagem que sofreu algum tipo de trauma, com dor de dente ou com dente cariado.

Morais et al. ${ }^{13}$ traçaram um levantamento sobre os serious games em uso na Odontologia. As autoras observaram que as tecnologias disponibilizadas eram restritas às seguintes temáticas: conceitos básicos de saúde bucal, higiene bucal de crianças e adultos, ida ao dentista e treinamento de profissionais. Havia 15 jogos disponíveis na $w e b$, sendo que três eram pagos e apenas um categorizado como opensource - softwares cujos códigos-fontes são disponibilizados (abertos).

Observou-se a predominância de jogos em ambiente $2 \mathrm{D}(73,3 \%)$. Quanto às temáticas, saúde bucal apresentou discreto número de ocorrências a mais $(53,84 \%)$ quando comparada com a temática higiene bucal $^{13}$. O público-alvo predominante foi o infantil.

Chama a atenção, segundo os resultados apresentados pelas autoras ${ }^{13}$, o percentual considerável $(26,66 \%)$ de softwares destinados a estudantes de odontologia. O jogo Odonto Quiz é exemplo. Foi concebido para apoio ao estudo da disciplina de prótese dentária. O jogo propõe a imersão do usuário em um enredo bastante comum no currículo de odontologia. O jogo foi proposto para estar integrado à prática da disciplina de prótese dentária, na qual os resultados virtuais obtidos pelo aluno possam ser trocados por bonificações na disciplina ${ }^{35}$.

O aplicativo Disney Magic Time, da ORAL-B, é gratuito e leva em consideração um tempo de escovação mais prolongado. Para desbloquear é preciso ter o produto Crest ou Oral-B Pro-Saúde Stages. Enquanto as crianças seguem as recomendações de seu dentista e escovam os dentes durante dois minutos, o temporizador faz com que a experiência seja mais divertida, porque está animado pelas personagens da Disney favoritas das crianças. As crianças ficarão satisfeitas por terem obtido novas conquistas a cada vez que receberem as figurinhas e acompanharem seu progresso diário no calendário de escovação. Entretanto, observa-se um foco muito grande dado ao entretenimento.

O aplicativo 'Caí, Perdi um dente... E daí?' aborda um assunto preocupante e, ao mesmo tempo, comum a responsáveis, educadores e crianças em fase escolar: a avulsão dentária. Comumente, esse assunto é tratado por meio de panfletos, cartilhas e animação. Tal aplicativo demonstrou ser eficaz na abordagem interativa quando combinada com a abordagem educativa ${ }^{22}$.

Como o público-alvo predominante é o infantil, não surpreende o uso de ludicidade, apelo ao imaginativo (e.g. fada do dente), criatividade, sonoridade, níveis diferenciados e graduados de dificuldades, customizações e a presença de personagens conhecidos por esse público, como os de filmes de animação (e.g. Elza e Ana, da animação Frozen; Barbie; e Po, da animação Kung Fu Panda).

\section{Discussão}

Nos dias atuais existe uma diversidade muito grande de jogos digitais, mas ainda são parcos aqueles que são desenvolvidos com fins educacionais, que tragam a proposta de ser um instrumento auxiliar para a formação de hábitos saudáveis e que, simultaneamente, engajem crianças e seus responsáveis.

O advento dos "jogos sérios" parece corroborar a tendência de acreditar nos benefícios dos videogames (e.g. GBL - Game Based Learning). O termo "jogo sério" foi utilizado pela primeira vez com o sentido próximo do que utilizamos hoje, no livro de Clark Abt 'Serious Games', publicado em 1970, anterior, portanto, ao nascimento dos videogames ${ }^{31}$.

Segundo o autor do livro, jogos sérios seriam jogos cuidadosamente pensados com o propósito explícito de educar, sendo esse o principal objetivo. O que não significa que os jogos sérios não sejam ou não devam ser divertidos.

$\mathrm{O}$ termo, segundo Djaouti ${ }^{31}$, foi adaptado em sua atual acepção para videogames no texto "The "Serious Games" Landscape', de Ben Sawyer ${ }^{32}$. No referido trabalho, o autor define um jogo sério como qualquer utilização significativa de um 
jogo computadorizado ou de recurso de jogo computadorizado, no qual a missão principal não seja o entretenimento ${ }^{32}$. Definição essa que é similar àquela encontrada em Michael e Chen ${ }^{33}$.

Os videogames proporcionam benefícios cognitivos, tais como: foco de atenção mais rápido e mais acurado, melhor desempenho em resolução espacial (processamento visual, rotação), habilidade de resolução de problemas e criatividade; motivacionais: visão persistente e otimista do meio ambiente; emocionais: melhora do humor e aumento de sentimentos positivos; sociais: aumento dos comportamentos sociais, como cooperação e engajamento cívico ${ }^{28}$. Videogames planejados para indivíduos portadores de condições que acarretam dificuldades de aprendizado (autismo e déficit de atenção) e videogames usados como métodos coadjuvantes em cuidados com a saúde e prevenção de doenças ${ }^{29}$.

$\mathrm{Na}$ publicação retratando o ensaio clínico ${ }^{23}$, as autoras escrevem o termo serious entre aspas. Embora seja um estudo de intervenção, não cabe avaliar, descrever ou classificar o artefato (game). Entretanto, o uso das aspas chama atenção. Fica evidente desde o início do desenho da pesquisa que se trata de uma intervenção e da subsequente avaliação de uma abordagem educativa por meio de um game. As autoras pontuam de modo prudente a possibilidade do uso dos "serious" games como auxiliar na educação em higiene oral ${ }^{24}$. Salientam, também, a necessidade de mais estudos de longo prazo para avaliar a efetividade de tal tecnologia com fins educacionais.

As ações educacionais em saúde e higiene bucal são feitas através de atividades curriculares nos cursos de graduação de Odontologia, atividades pertinentes aos serviços prestados pela equipe de Saúde Bucal da Estratégia Saúde da Família (ESF), em atendimento às exigências dos programas. Para tal, fazem uso de panfletos, banners e palestras com os profissionais de saúde.

É prudente levar em conta que a conciliação dessas atividades educativas com a dinâmica dos jogos possa ser uma boa estratégia, uma vez que há pesquisas que evidenciam um aprendizado efetivo no uso desse método ${ }^{34}$.

Ações educativas, quando empregadas em um ambiente dinâmico, tendem a produzir melhores resultados. Criar esse ambiente por meio de um jogo sério envolve múltiplas variáveis: uma equipe multiprofissional especializada (e.g. o designer de games), tempo e orçamento. Admite-se a possibilidade de, ao ser dada atenção a essas variáveis, perder-se de vista o fundamento conceitual de um serious game: a ação pedagógica.
Ainda pairam limitações metodológicas com relação aos serious games, inclusive por aspectos conceituais - e.g. a tradução do termo para o português ainda não é consenso, por entenderem que o termo 'jogo sério' não abrange toda significância do seu correspondente em inglês.

Três pressupostos estão presentes em um serious game: mídia interativa, jogo e ação pedagógica. Existe um fator que emerge quando os serious games são analisados e que foi apontado em muitos dos resultados aqui apresentados. Embora o uso de um personagem, um super-herói ou avatar, por exemplo, seja predominante e estratégico, e as explicações dadas no transcorrer do jogo sejam bem elaboradas, organizadas e com linguagem adequada, a ação pedagógica precisa comungar com fatores de motivação intrínsecos ou extrínsecos ao jogo. Essa também foi a opinião dos psicólogos que avaliaram o artefato, cujo resultado foi que o jogo apresenta efeito positivo motivador sobre o aprendizado das crian$\mathrm{ças}^{26}$. Uma das propostas do jogo PEPE ${ }^{19}$ é que o personagem Supersaliva seja um elo entre o paciente e o dentista e que, para avançar de fase, o paciente demonstre ao dentista que aprendeu ou desenvolveu as habilidades esperadas. Com isso, ele ganha premiações (motivação extrínseca) e o progresso de fase.

Quando se falava na participação dos pais na educação de seus filhos, enquanto promotores de aprendizado, segundo Carvalho ${ }^{36}$, não se consideravam: as mudanças históricas e a diversidade cultural nos modos de educação e reprodução social; a diversidade de arranjos familiares $\mathrm{e}$ as desvantagens materiais e culturais de grande parte das famílias. O avanço da tecnologia e a popularização das redes sociais levam-nos a repensar essas considerações de Carvalho ${ }^{36}$, ao mesmo tempo que nos desafiam a levarmos em conta as mudanças nos modos de educação e a diversidade de arranjos familiares.

Os jogos sérios, segundo ficou evidenciado e, em conformidade com o objetivo proposto nesta revisão integrativa, foram desenvolvidos estritamente dentro de seus respectivos objetivos, das suas metodologias conceituais de desenvolvimento, de sua abordagem pedagógica e de acordo com os métodos avaliativos concernentes aos artefatos. A qualidade bastante variada dos jogos disponibilizados quanto a design e arte, enredo e ambiente de imersão, jogabilidade, transferência, incorporação; e a quantidade de artigos incluídos na pesquisa reforçam tal tendência. A novidade que se percebe agora é a convergência do uso de tais tecnologias aplicadas à saúde pública. 
Conciliar recursos tecnológicos com novas formas de educação em saúde é uma estratégia que não pode ser negligenciada tanto por quem trabalha em saúde pública quanto por gestores. Embora a aplicação desses recursos tecnológicos na saúde pública seja incipiente, eles já apresentam algumas características, entre as quais: o olhar voltado não apenas para o cognitivo e para o entretenimento, mas, também, para o gerenciamento e o monitoramento de doenças crônicas, como hipertensão, por exemplo.

Aplicativos para acompanhamento de gestantes de alto risco, com vistas a diminuir a mortalidade materno-infantil, e aplicativos voltados para controle da pressão arterial são exemplos de como tais tecnologias podem ser potentes aliadas na promoção da saúde.

Aplicativos médicos baseados em smartphones ( $m$ Health) estão facilitando o autogerenciamento da hipertensão ${ }^{37}$. Esse mesmo autor afirma que a maioria dos aplicativos projetados para hipertensão prima pelo gerenciamento de saúde por meio do rastreamento da pressão arterial. Os consumidores têm uma forte tendência de fazer o download e avaliar favoravelmente aplicativos para medir a pressão arterial e a frequência cardíaca. Afirma, porém, a necessidade de uma adequada validação desses recursos tecnológicos para tais fins ${ }^{37}$.

Esse cenário tem despertado a comunidade acadêmica. Em recente estudo, Plate et al. ${ }^{38}$ destacam a tal relevância clínica em saúde pública. Por esse prisma, o estudo apoia a regulação pelos devidos órgãos públicos para definição de padrões para tecnologias $m$ Health seguras e validadas ${ }^{38}$.

\section{Considerações finais}

Serious games voltados para a saúde e a higiene bucal de bebês, gestantes e que eduquem os usuários a visitas regulares e preventivas ao consultório dentário ainda são incipientes quando comparados à grande quantidade de aplicativos disponibilizados pela Play Store, na qual a principal atenção é dada ao entretenimento. De modo semelhante, serious games têm a proposta de serem ferramentas domésticas que trabalham simultaneamente com crianças e seus responsáveis na adoção de hábitos saudáveis de higiene bucal.

Dessa forma, evidencia-se uma área que requer um olhar criterioso, metodológico-pedagógico, em que os serious games e aplicativos sirvam de apoio para atividades de promoção, prevenção e educação em saúde.

Apesar da escassez de publicações sobre o assunto, explorar recursos tecnológicos como meio de educação em higiene bucal infantil sinaliza uma área do conhecimento com potencial acadêmico e com aplicações na saúde pública.

Novas revisões devem ser empreendidas, a fim de confirmar o impacto dos serious games quanto à educação e à adoção de hábitos saudáveis em higiene bucal em ambiente familiar. O reduzido número de estudos utilizados para esta pesquisa pode ser interpretado como uma limitação para a generalização dos dados. Todavia, pode ser útil, também, como subsídio para que mais tecnologias sejam desenvolvidas e mais estudos sejam feitos.

\section{Colaboradores}

ER Morais participou da concepção, planejamento, análise, interpretação do protocolo PRISMA e redação do trabalho. CMAC Vergara, participou na interpretação dos dados e análise da redação do presente artigo. FO Brito foi outro revisor do protocolo PRISMA, contribuiu nos aspectos de formatação e discussão de eleição de alguns artigos. HAC Sampaio trouxe contribuições na revisão crítica da seção discussão. 


\section{Referências}

1. Kebritchi M, Hirumi A. Examining the pedagogical foundations of modern educational computers games. Computers Education 2008; 51(4):1729-1743.

2. Kebritchi M, Hirumi A, Bai H. The effects of modern math computer games on learners' math achievement and math course motivation in a public high school setting [Internet]. 2008 [acessado 2016 Ago 16.] Disponível em: assets.pearsonglobalschools.com/filevault/teacher_degrees/custom_images/custom/BasalEmails/dimension_m/media/UCFResearch_Brief. pdf

3. Papastergio M. Exploring the potential of computer and video games for health and physical education: a literature review. Computers Education 2009; 53(3):603-622.

4. Tarouco LMR, Fabre MCJM, Konrath MLP, Grando AR. Objetos de aprendizagem para M-learning. In: Anais do Congresso Nacional de Tecnologia da Informação e Comunicação. Florianópolis: SUCESU, 2004.

5. Traxler J. Defining, discussing and evaluationg mobile learning: the moving finger writes and having writ. IRRODL 2007; 8:2.

6. Moura A. Geração móvel: um ambiente de aprendizagem suportado por tecnologias móveis para "Geração Polegar". In: VI Conferência Internacional de TIC na Educação 2010; 49-77.

7. Valentim H. Para uma compreensão do mobile learning. Reflexão sobre a utilidade das tecnologias móveis na aprendizagem informal e para a construção de ambientes pessoais de aprendizagem. Gestão de sistemas de e-learning [dissertação] Lisboa: Universidade Nova de Lisboa; 2009.

8. Klopfer E, Osterweil S, Salen K. Moving learning games forward: obstacles, opportunities, and openness. The education arcade: MIT; 2009.

9. Machado LS, Moraes RM, Nunes F. Serious games para saúde e treinamento imersivo. Abordagens Práticas de Realidade Virtual e Aumentada 2009; 1:31-60.

10. Michael D, Chen S. Serious Games: games that educate, train and inform. Course Technology PTR; 2005.

11. Rosser Jr JC, Lynch PJ, Haskamp LA, Yalif A, Gentile DA, Giammaria L. Are video game players better at a laparoscopy surgery? Presentation at Medicine Meets Virtual Reality Conference, Newport Beach, CA; 2004.

12. Machado LS, Valença NMG, Morais AM. Um serious game para educação em saúde bucal de bebês. Tempus Actas Saúde Colet 2016; 10(2):167-188.

13. Morais AM, Machado LS, Valença, AMG. Serious game na odontologia: aplicações, características e possibilidades. In: Anais do Congresso Brasileiro de Informática em Saúde; Porto de Galinhas, 2010 out 18-22. São Paulo: Sociedade Brasileira de Informática em Saúde.

14. Morais AM, Machado LS, Valença AMG. Planejamento de um serious games voltado para saúde bucal em bebês. Rev Informática Teórica Aplicada 2011; 18(1):158-175

15. Morais AM, Machado LS, Valença AMG. Definindo a abordagem de comunicação no planejamento de um serious games voltado para saúde bucal em bebês. In: Anais do 30. Congresso da Sociedade Brasileira de Computação; 5. Workshop de Informática Médica. São Paulo: Sociedade Brasileira de Informática em Saúde; 2010.
16. Whittemore R, Knafl K. The integrative review: updated methodology. J Adv Nurs 2005; 52(5):546-553.

17. Morais AM. Planejamento e desenvolvimento de um serious game voltado ao ensino de saúde bucal em bebês. [dissertação]. João Pessoa: Universidade Federal da Paraíba; 2011.

18. Preece J, Rogers Y, Sharp H. Design de interação: além de interação homem-computador. $3^{\text {a }}$ ed. Porto Alegre: Bookman; 2013.

19. Vasconcelos Filho JE, Rocha GST, Sousa AG, Holanda EP, Silva EM, Macambira NA. Um jogo sério de apoio ao tratamento odontológico de crianças especiais. In: Anais do 13. Simpósio brasileiro de jogos e entretenimento digital. Porto Alegre; 2014 Nov 12-14. p. 625628.

20. Rodrigues HF. Aplicando sistemas hápticos em serious games: um jogo para educação em higiene bucal [dissertação]. João Pessoa: Universidade Federal da Paraíba; 2011 .

21. Rodrigues HF, Machado LS, Valença AMG. Uma proposta de serious game aplicado à educação em saúde bucal. In: Anais do Workshop de Realidade Virtual e Aumentada. Santos; 2009.

22. Rodrigues MH. Criação, desenvolvimento e aplicação de serious game educativo para prevenção em saúde bucal infantil [dissertação]. Bauru, São Paulo: Universidade de São Paulo; 2014

23. Aljafari A, Gallagher JE, Hosey MT. An oral health education video game for high caries risk children: study protocol for a randomized controlled trial. Trials 2015; 16(1):237.

24. Aljafari A, Gallagher JE, Hosey MT. Can oral health education be delivered to high-caries-risk children and their parents using a computer game? A randomised controlled trial. Int J Paediatr Dent 2017; 27(6):476-485

25. Dotta EAV, Campos JADB, Garcia PPNS. Elaboração de um jogo digital educacional sobre saúde bucal direcionado para a população infantil. Pesquisa Bras Odontopediatr Clínica Integrada 2012; 12(2):209-215.

26. Schuytema P. Design de games: uma abordagem prática. São Paulo: Cengage Learning; 2008.

27. Battaiola AL. Jogos por computador: histórico, relevância tecnológica e mercadológica, tendências e técnicas de implementação. In: Anais da 19. Jornada de Atualização em Informática. Curitiba: Pontifícia Universidade Católica do Paraná; 2000 Jun 17-21. p. 83-122.

28. Granic I, Lobel A, Engels RCME. The benefits of playing video games. Am Psychol 2014; 69(1):66-78.

29. Griffiths $\mathrm{M}$. The educational benefits of videogames. J Educ Health 2002; 20(3):47-51.

30. Camargo MBJ, Barros JD, Frazão P, Matejasevich A, Santos IS, Peres MA, Peres KG. Preditores da realização de consultas odontológicas de rotina e por problema em pré-escolares. Rev Saúde Pública 2012; 46(1):87-97.

31. Djaouti D, Alvarez J, Jessel JP, Rampnoux O. Origins of serious games. In: Ma M, Oikonomou A, Jain LC, editores. Serious games and edutainment applications. Londres: Springer; 2011. p. 25-43.

32. Sawyer B. The "Serious Games" Landscape. Instructional \& Research Technology Symposium for Arts, Humanities and Social Sciences; 2007. 
33. Michael D, Chen S. Serious Games: games that educate, train, and inform. Ohio: Course Technology; 2006.

34. Johnsen K, Raij A, Stevens A, Lind DS, Lok B. The validity of a virtual human experience for interpersonal skills education. In: Proceedings of the SIGCHI conference on Human factors in computing systems; 2007 Abr:1049-1058.

35. Vasconcelos Filho JE, Salomão J, Madeira B, Palacio I, Sousa AG, Macambira NA. Odonto Quiz: um jogo sério de apoio ao estudo da disciplina de próteses dentárias. In: XIII SBGames. Porto Alegre; 2014 Nov 12-14. p. 946-949.

36. Carvalho MEP. Modos de educação, gênero e relações escola-família. Cad Pesqui 2004; 34(121):41-58.

37. Kumar N, Khunger M, Gupta A, Garg N. A content analysis of smartphone - based applications for hypertension management. J Am Soc Hypertens 2015; 9(2):130-136.

38. Plante TB, Urrea B, MacFarlane ZT, Blumenthal RS, Miller III ER, Appel LJ, Martin SS. Validation of the instant blood pressure smartphone app. JAMA Intern Med 2016; 176(5):700-702.

Artigo apresentado em 22/11/2017

Aprovado em 14/11/2018

Versão final apresentada em 15/11/2018 